\title{
Health minister ends special access to prescription heroin
}

$\mathrm{H}$ ealth Minister Rona Ambrose has changed a federal program so doctors can no longer prescribe heroin or any other illegal drugs to their patients, despite international studies indicating that the active ingredient in heroin, diacetylmorphine, is more cost-effective than methadone and improves the lives of long-term users.

Ambrose amended Health Canada's Special Access Programme on Oct. 3 to "more clearly align" it with the National Anti-Drug Strategy and other government programs, the minister told a news conference in Toronto, Ontario.

"Our goal must be to take heroin out of the hands of addicts, not put it in their arms," Ambrose said.

Ambrose learned in September, shortly after assuming her new cabinet portfolio, that Health Canada had approved an application from doctors affiliated with Providence Health Care in British Columbia to provide prescription heroin to 21 patients with long-term addictions. The patients had previously participated in the Study to Assess Longer-term Opioid Medication Effectiveness (SALOME), a phase II clinical trial. During the study to test the effectiveness of hydromorphone versus diacetylmorphine, the participants received diacetylmorphine, the active ingredient in heroin.

Neither methadone nor repeated attempts at residential treatment programs has helped the patients, said Dr. Martin Schechter, a professor at the University of British Columbia's School of Population and Public Health. "The 21 individuals represent people who at the end of their treatment period were doing extremely well on the treatment [diacetylmorphine], and the physicians at the clinic thought that in the best interests of the patients, they should be continued on the treatment," said Schechter, who is also a scientist with Providence Health Care.

In a study published in $C M A J$ in 2012 (www.cmaj.ca/lookup/doi/10

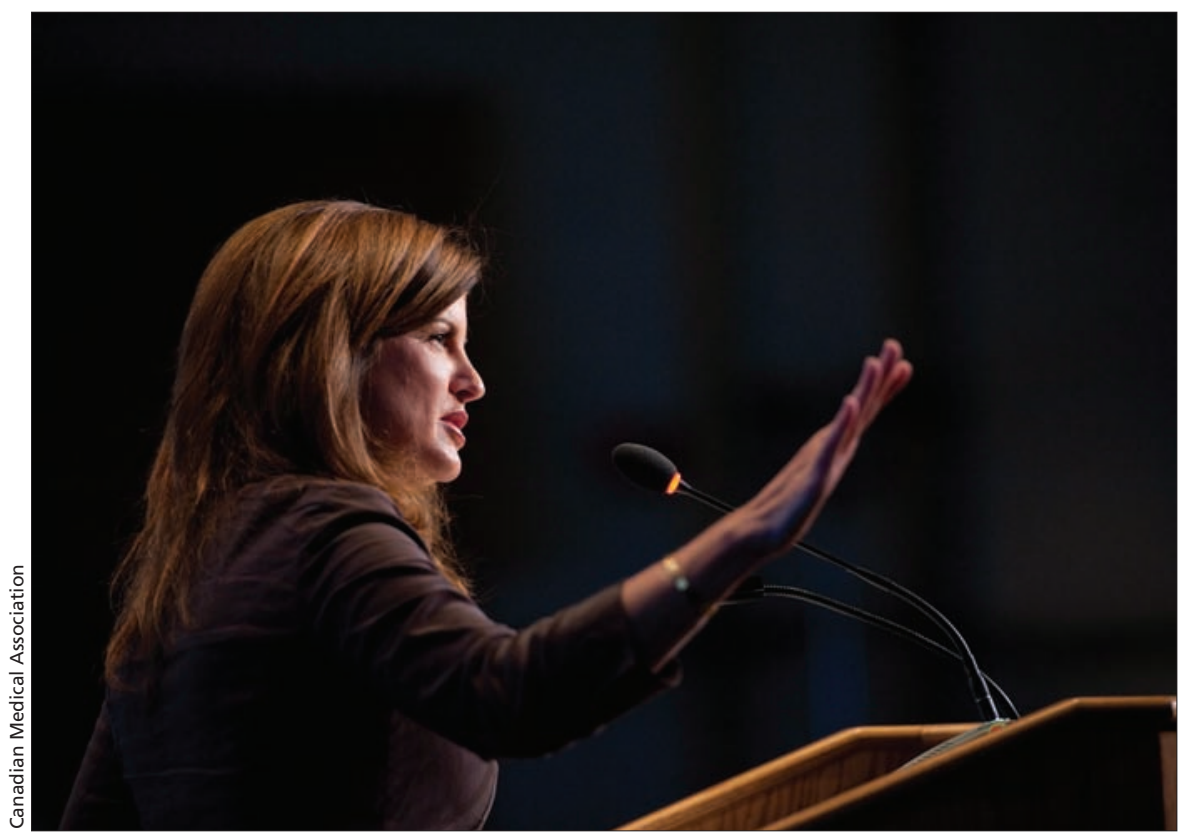

Health Minister Rona Ambrose amended Health Canada's Special Access Programme on Oct. 3 to "more clearly align" it with the National Anti-Drug Strategy and other government programs.

$.1503 /$ cmaj.110669), researchers from Providence Health Care used mathematical modelling and data from the North American Opiate Medication Initiative (NAOMI) study to predict that patients receiving diacetylmorphine would live longer, and societal costs would decrease, compared with patients taking methadone for maintenance as part of their heroin addiction treatment strategy.

Trials in Switzerland, Germany, the Netherlands, Spain and England all found similar results, said Schechter. In each of those countries, after the trials concluded, doctors were able to prescribe heroin for the patients who had been enrolled and done well on it, he said. Denmark did not even conduct a trial, but simply acted on the best international evidence to open clinics where patients with heroin addictions can receive diacetylmorphine.

"Canada remains the sole country who has studied this scientifically but then shut the door on its use subsequent to the trial," Schechter said.
At her news conference, Ambrose was flanked by Dr. Meldon Kahan, an associate professor at the University of Toronto's Department of Family Medicine, who referred to the use of medical heroin as being among "flawed treatment approaches."

If Ambrose is questioning the science behind the NAOMI study, which international experts have extensively peer-reviewed, she is "barking up the wrong tree," said Schechter. "By bringing an expert into a press conference and criticizing NAOMI, I think she was suggesting she does not have faith in the scientific evidence - when in fact the science is overwhelming."

Schechter suggested the federal Conservative government is motivated by ideological factors, rather than science, in making this decision, which he equated to its attempts to shut down the supervised injection site InSite in Vancouver, British Columbia. The Supreme Court later overturned the federal position on InSite.

"I think it has to do with politics and 
getting elected and playing to your base, but you'd better ask a political scientist rather than me," Schechter said about the government's motivation in changing the special access provisions.

This decision, too, may well be overturned, said Schechter, who described his reaction to being unable to prescribe what he views as the best treatment for his patients as "extreme frustration."

"I ultimately think this decision will be challenged," he said.

When justifying the changes to the Special Access Programme, Ambrose alluded to the death of Canadian actor Cory Monteith from a heroin and alco- hol overdose in Vancouver to assert that heroin addiction is a far-reaching problem that affects many people.

"The prime minister and I do not believe we are serving the interests of those who are addicted to drugs or those who need our help by giving them the very drugs they are addicted to," she said.

The program was never intended to provide heroin to people with addictions, but is designed to provide emergency access to life-saving drugs, Ambrose said. The minister also referred people with addictions to alternative treatments such as acupuncture, and suggested that doctors wanting to prescribe diacetylmorphine approach their provincial regulatory colleges.

The changes to the federal program will not affect clinical trials involving illegal drugs, such as the SALOME trial, Ambrose said. The patients currently taking heroin prescribed under the Special Access Programme will be able to continue to until the end of the 90-day period for which access was authorized, but their prescriptions will not be renewed. - Laura Eggertson, CMAJ

CMAJ 2013. DOI:10.1503/cmaj.109-4626 